\title{
Psychological Factors Influence the Overlap Syndrome in Functional Gastrointestinal Disorder and Quality of Life among Psychiatric Patients in South Korea
}

\author{
Sang-Yeol Lee', Han-Seung Ryu², Suck-Chei $\mathrm{Choi}^{2}$, and Seung-Ho Jang ${ }^{1 凶}$ \\ ${ }^{1}$ Department of Psychiatry, School of Medicine, Wonkwang University, Iksan, Republic of Korea \\ ${ }^{2}$ Department of Internal Medicine, School of Medicine, Wonkwang University, Iksan, Republic of Korea
}

\begin{abstract}
Objective The aim of this study was to investigate the predictor variables that could influence overlap syndrome in functional gastrointestinal disorders (FGID) among psychiatric patients.

Methods Data collected from 170 outpatients visiting the psychiatric clinic at a university hospital. FGIDs were screened according to the Rome III questionnaire-Korean version. Demographic factors were investigated, and psychosocial factors were evaluated using the Hospital Anxiety Depression Scale, Patient Health Questionnaire-15, Childhood Trauma Questionnaire-Korean and the Short form health survey. Chi-squared test, Student's t-test, one-way ANOVA, and Pearson's correlation test were used as statistical analysis methods.

Results There were no differences in the epidemiologic data between the two groups divided according to the FGID status. In those with FGID overlap syndrome, FD-NERD was most common $(n=29)$, followed by IBS-NERD $(n=20)$. Patients with overlap syndrome had the highest depressive, anxiety, and somatic symptoms. The overlap syndrome group had the lowest physical component summary and mental component summary. FGID symptom severity was significantly correlated with PCS and MCS in the overlap syndrome group.

Conclusion Psychological factors are associated with the overlap syndrome of FGID. Acknowledging this common comorbidity may facilitate the recognition and treatment of patients with FGID.

Psychiatry Investig 2020;17(3):262-267
\end{abstract}

Key Words Functional gastrointestinal disorder, Overlap syndrome, Depression, Anxiety, Quality of life.

\section{INTRODUCTION}

Functional gastrointestinal disorder (FGID) refers to chronic or recurrent gastrointestinal syndromes that are not explained by anatomical or physiological abnormalities. ${ }^{1}$ FGID includes irritable bowel syndrome (IBS), functional dyspepsia (FD), functional heartburn (FH), and functional constipation (FC) and can cause serious social and economic burdens. As a representative FGID, IBS affects $10-20 \%$ of the general population $^{2}$ and is known to result in a very low quality of life, similar to the quality of life in patients with chronic renal failure or ischemic heart disease. ${ }^{3,4}$

Received: October 18, 2019 Revised: December 16, 2019

Accepted: December 23, 2019

$\triangle$ Correspondence: Seung-Ho Jang, MD

Department of Psychiatry, School of Medicine, Wonkwang University, $895 \mathrm{Mu}$ wang-ro, Iksan 54538, Republic of Korea

Tel: +82-63-859-1044, Fax: +82-63-857-1043, E-mail: sh-jang82@hanmail.net

(a) This is an Open Access article distributed under the terms of the Creative Commons Attribution Non-Commercial License (https://creativecommons.org/licenses/bync/4.0) which permits unrestricted non-commercial use, distribution, and reproduction in any medium, provided the original work is properly cited.
Psychosocial factors, including stress, play a very important role in the manifestation of FGID. ${ }^{5}$ In addition, when FGID is accompanied by mental illness such as depressive symptoms or anxiety, the symptoms become much worse. ${ }^{6}$ In a previous study, the prevalence of depressive symptoms and anxiety in IBS patients were very high, at $22 \%$ and $30 \%$, respectively. ${ }^{7}$ However, in the busy outpatient environment, assessment of these psychosocial factors is commonly overlooked. It is also difficult for patients to understand the importance of psychosocial factors, and many patients hide psychological symptoms due to concerns about the stigma of mental illness.

There have been several studies on FGID in patients with psychiatric illnesses. Oreški et al. ${ }^{8}$ reported that, in patients with schizophrenia, gastrointestinal symptoms are the second most common type after neurological symptoms, and Molloy Manning-Courtney ${ }^{9}$ reported that $24 \%$ of autism spectrum disorder patients showed at least one chronic gastrointestinal symptom. In a study by Lydiard et al. ${ }^{10}$ the prevalence of FGID in panic disorder patients was very high compared to the general population, while Noyes et al. ${ }^{11}$ reported that the time of 
onset for gastrointestinal symptoms and panic disorder was similar, and that gastrointestinal symptoms were lessened when panic symptoms improved.

In the clinical field, two or more FGIDs can often be observed in the same patient and such cases of multiple concurrent FGIDs are referred to as overlap syndrome of FGID (hereafter, overlap syndrome). ${ }^{12}$ In a study by Locke et al., ${ }^{13} 1-8 \%$ of community people experienced 2-3 FGIDs, and Choung et al. ${ }^{14}$ reported that $17 \%$ of individuals experience two or more FGIDs, showing that a lot of people suffer from overlap syndrome.

In spite of the high prevalence of FGID in psychiatric patients and the close relationship between FGID and psychosocial factors, there have been almost no studies on overlap syndrome. Therefore, in this study, we aimed to investigate the prevalence of overlap syndrome in psychiatric patients and to explore its psychosocial characteristics.

\section{METHODS}

\section{Participants}

Participants consisted of 170 psychiatric patients who visited the mental health department of a single university hospital. The study was conducted between June and December 2017, and after excluding 26 participants due to insincere responses, data from the remaining 144 participants was analyzed. The inclusion criteria were 1) patients aged 18-70 years, and 2) patients who had been diagnosed with schizophrenia, mood disorder (major depressive disorder, bipolar disorder), anxiety disorder (generalized anxiety disorder, panic disorder), neurocognitive disorder (mild cognitive disorder), or alcohol use disorder by a psychiatrist based on Diagnostic and Statistical Manual of Mental Disorders-5 (DSM-5) criteria. ${ }^{15}$ Exclusion criteria were 1) patients showing severe aggression, and 2) patients who could not read or understand the questionnaire. After investigating the participants' demographic characteristics and psychosocial factors, participants were classified into FD, FC, and IBS groups based on the Rome III diagnostic criteria, and a non-erosive reflux disease (NERD) group was selected based on the Montreal criteria. ${ }^{16}$ Participants provided written consent to participate in the study after hearing an explanation of the study objectives. This study was approved by a Wonkwang University Hospital Institutional Review Board (IRB WKUH 2018-04-010-009).

\section{Measures}

\section{Hospital Anxiety and Depression Scale (HADS)}

Anxiety and depressive symptoms were assessed using the Hospital Anxiety Depression scale (HADS) developed by Zig- mond and Snaith. ${ }^{17}$ HADS consists of 14 questions in total, where the 7 odd-numbered questions relate to anxiety and the 7 even-numbered questions relate to depressive symptoms. Each question is rated on a 4-point Likert scale from 0 points ('Strongly disagree') to 3 points ('Strongly agree'). The scores for anxiety and depressive symptoms are each in the range $0-21$, where higher scores indicate more severe symptoms. The validity and reliability study in Korean was performed by Oh et al. ${ }^{18}$

\section{Childhood Trauma Questionnaire-Short Form (CTQ-SF)}

The CTQ-SF is a 28 -item self-report inventory developed to measure five types of abuse or neglect in childhood or adolescence. ${ }^{19}$ Respondents are queried on items with a 5-point, likert-type answer format ranging from never true (score $=1)$ to very often true (score=5). Each subscale contains five items and an additional three items are intended to measure any tendency to minimize or deny the abuse. Its validity and reliability was confirmed in Korean by Kim et al. ${ }^{20}$

\section{Patient Health Questionnaire-15 (PHQ-15)}

The PHQ-15 is a convenient and very brief self-rating somatic symptom scale. ${ }^{21}$ It assesses 15 somatic symptoms or symptom clusters that account for more than $90 \%$ of all physical complaints reported by outpatients. Each item is rated on a scale from 0 to 2 , and scores are summed to return a final score ranging from 0 to 30 . The validity and reliability study in Korean was performed by Han et al. ${ }^{22}$

\section{Short Form Health Survey-36 (SF-36)}

The Short Form Health Survey (SF-36) is widely used to evaluate people's health-related quality of life. ${ }^{23}$ It includes 8 items: physical functioning (PF), role limitations due to physical health problems (PR), bodily pain (BP), perceptions of general health $(\mathrm{GH})$, vitality (VT), social functioning (SR), role limitations due to emotional problems (ER), and mental health $(\mathrm{MH})$. The score ranges from 0 to 100 , with 0 indicating the worst and 100 representing the best condition. The 8 items were divided to obtain scores for physical condition (PCS) and mental condition (MCS). Its validity and reliability was confirmed in Korean by Han et al. ${ }^{24}$

\section{Functional bowel severity disorder index (FBSDI)}

The severity of IBS was scored using the validated functional bowel severity disorder index (FBSDI) developed by Drossman et al., ${ }^{25}$ which provides an easy to use scale to appraise illness severity in patients with FGID. It is comprised of three variables: current pain (by visual analog scale), diagnosis of chronic abdominal pain, and the number of physician visits in the past 6 months. 


\section{Statistical analyses}

Statistical analyses were performed using the SPSS 21.0 (IBM Corp., Armonk, NY, USA). Continuous variables were expressed as mean \pm standard deviation, whereas categorical variables were expressed as numbers and percentages. A oneway ANOVA was used to compare the parametric quantitative variables, followed by a Bonferroni test for post hoc analysis to further examine the differences among the groups. To measure the effect size, partial $\eta^{2}$ values were calculated using cut-off norms provided by Cohen. ${ }^{26}$ We used the Pearson's correlation test to assess correlations between the psychological variables.

\section{RESULTS}

\section{Demographic characteristics of participants}

Of the 144 participants, the distribution of psychiatric disorders was as follows: schizophrenia $(n=66)$, mood disorder $(n=50)$, anxiety disorder $(n=7)$, neurocognitive disorder $(n=9)$, and alcohol use disorder $(n=12)$. There were no differences in demographic and clinical characteristics according to FGID (Table 1).

\section{Prevalence of overlap syndrome of FGID in psychiatric patients}

Cases of overlap syndrome involving 3 or more FGIDs included IBS-FD-NERD $(n=12)$ and FC-FD-NERD $(n=5)$. Overlap syndrome involving 2 or more FGIDs included FD-NERD $(n=29)$, IBS-NERD $(n=20)$, IBS-FD $(n=12)$, FC-FD $(n=5)$, and FC-NERD (n=13) (Figure 1).

\section{Comparison of psychological variables among the groups}

Overlap syndrome group had a higher anxiety score (11.41士 6.36) than non-overlap (7.41 \pm 4.63$)$ and healthy control groups $(6.51 \pm 5.76)\left(\mathrm{F}=10.132, \mathrm{p}<0.001, \eta^{2}=0.126\right)$. Overlap syndrome group had higher depression score in HADS (11.45 \pm 5.47$)$ than non-overlap $(8.51 \pm 4.64)$ and healthy control group (7.83 \pm 5.33$)$ $\left(\mathrm{F}=6.616, \mathrm{p}<0.01, \eta^{2}=0.086\right)$. Overlap syndrome group had high-

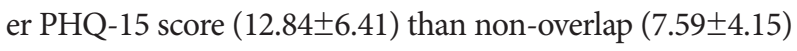
and healthy control group $(4.90 \pm 5.32)(\mathrm{F}=27.898, \mathrm{p}<0.001$, $\left.\eta^{2}=0.284\right)$ (Table 2).

\section{Comparison of health-related quality of life among the groups after adjusted for age and sex}

The overlap syndrome group had lower ER score (47.73 \pm $31.35)$ than the healthy control group $(65.48 \pm 33.73)(\mathrm{F}=4.691$, $\left.\mathrm{p}<0.05, \eta^{2}=0.062\right)$ and lower MH score $(40.00 \pm 22.66)$ than the non-overlap syndrome $(55.14 \pm 16.68)$ and healthy control group $(56.89 \pm 21.33)\left(\mathrm{F}=9.505, \mathrm{p}<0.001, \eta^{2}=0.119\right)$. The over- lap syndrome group also had a smaller VT score (29.32 21.79$)$ than the non-overlap syndrome $(45.41 \pm 18.57)$ and healthy control group $(49.44 \pm 19.49)\left(\mathrm{F}=13.733, \mathrm{p}<0.001, \eta^{2}=0.163\right)$.

Table 1. Demographic characteristics of participants

\begin{tabular}{|c|c|c|c|c|}
\hline & $\begin{array}{l}\text { FGID-negative } \\
\qquad(\mathrm{N}=63)\end{array}$ & $\begin{array}{l}\text { FGID-positive } \\
\qquad(\mathrm{N}=81)\end{array}$ & $\chi^{2} / \mathrm{t}$ & $\mathrm{p}$ \\
\hline Sex & & & 0.323 & 0.570 \\
\hline Male & $32(50.8)$ & $45(55.6)$ & & \\
\hline Female & $31(49.2)$ & $36(44.4)$ & & \\
\hline Age & & & 0.890 & 0.375 \\
\hline Mean $\pm S D$ & $43.22 \pm 15.13$ & $45.44 \pm 14.52$ & & \\
\hline Marital status & & & 1.460 & 0.834 \\
\hline Unmarried & $26(41.3)$ & $37(45.7)$ & & \\
\hline Married & $24(38.1)$ & $30(37.0)$ & & \\
\hline Separated & $2(3.2)$ & $2(2.5)$ & & \\
\hline Divorced & $6(9.5)$ & $9(11.1)$ & & \\
\hline Bereaved & $5(7.9)$ & $3(3.7)$ & & \\
\hline Education (years) & & & 0.356 & 0.837 \\
\hline Low $(<10)$ & $12(19.0)$ & $13(16.0)$ & & \\
\hline Middle (10-13) & $22(34.9)$ & $30(37.1)$ & & \\
\hline High (>13) & $29(46.1)$ & $38(46.9)$ & & \\
\hline Diagnosis & & & 6.717 & 0.152 \\
\hline Schizophrenia & $36(57.1)$ & $30(37.0)$ & & \\
\hline Mood & $18(28.6)$ & $32(39.5)$ & & \\
\hline Anxiety & $2(3.2)$ & $5(6.2)$ & & \\
\hline Cognitive & $4(6.3)$ & $5(6.2)$ & & \\
\hline AUD & $3(4.8)$ & $9(11.1)$ & & \\
\hline Smoking & & & 0.008 & 0.927 \\
\hline Yes & $19(30.2)$ & $25(30.9)$ & & \\
\hline No & $44(69.8)$ & $56(69.1)$ & & \\
\hline Alcohol & & & 0.814 & 0.606 \\
\hline Yes & $29(46.0)$ & $39(48.1)$ & & \\
\hline No & $34(54.0)$ & $42(51.9)$ & & \\
\hline
\end{tabular}

SD: standard deviation, FGID: functional gastrointestinal disorder, AUD: alcohol use disorder

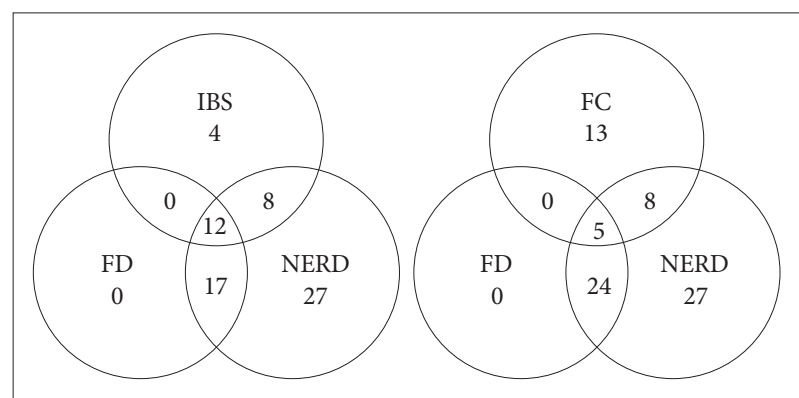

Figure 1. Prevalence of overlap syndrome of FGID in psychiatric patients $(\mathrm{N}=81)$. NERD: nonerosive reflux disease, FD: functional dyspepsia, FC: functional constipation, IBS: irritable bowel syndrome. 
In addition, the overlap syndrome group had lower BP score $(42.04 \pm 33.46)$ than healthy control group $(59.72 \pm 34.08)(\mathrm{F}=$ $\left.3.800, \mathrm{p}<0.05, \eta^{2}=0.051\right)$ as well as lower physical condition (PCS) score $(42.32 \pm 25.93)$ than the healthy control group $(56.77 \pm 24.13)\left(\mathrm{F}=4.908, \mathrm{p}<0.01, \eta^{2}=0.065\right)$. The overlap syndrome group had a reduced general health $(\mathrm{GH})$ score $(37.95 \pm$ $21.30)$ compared to the non-overlap syndrome $(50.27 \pm 16.79)$ and healthy control group $(53.97 \pm 21.87)(\mathrm{F}=8.168, \mathrm{p}<0.001$, $\left.\eta^{2}=0.104\right)$. Finally, the overlap syndrome group had lower mental health (MCS) score $(42.11 \pm 17.07)$ than the non-overlap syndrome $(51.48 \pm 12.41)$ and the healthy control group $(56.59 \pm 14.97)\left(\mathrm{F}=12.109, \mathrm{p}<0.001, \eta^{2}=0.147\right)$ (Table 3).

\section{Bivariate associations between severity of FGID and health related quality of life among overlap syndrome group}

MCS ( $\mathrm{r}=0.734, \mathrm{p}<0.01)$, IBS-severity $(\mathrm{r}=-0.381, \mathrm{p}<0.01)$, NERD-severity $(r=-0.395, \mathrm{p}<0.01)$, FD-severity $(\mathrm{r}=-0.298, \mathrm{p}<$ $0.01)$ and FC-severity $(r=-0.415, \mathrm{p}<0.01)$ were each moderately to strongly associated with PCS. IBS-severity $(r=-0.403$, $\mathrm{p}<0.01)$, NERD-severity $(\mathrm{r}=-0.441, \mathrm{p}<0.01)$, FD-severity $(\mathrm{r}=$ $-0.402, \mathrm{p}<0.01)$ and FC-severity $(\mathrm{r}=-0.386, \mathrm{p}<0.01)$ also had a moderate to strong association with MCS (Table 4).

Table 2. Comparison of psychological variables among groups

\begin{tabular}{|c|c|c|c|c|c|c|}
\hline Variables & $\begin{array}{c}\text { Non-FGID }{ }^{\mathrm{a}} \\
(\mathrm{N}=63)(\mathrm{mean} \pm \mathrm{SD})\end{array}$ & $\begin{array}{l}\text { Non-overlap FGID } \\
(\mathrm{N}=35)(\text { mean } \pm \mathrm{SD})\end{array}$ & $\begin{array}{c}\text { Overlap FGID }{ }^{c} \\
(\mathrm{~N}=46)(\text { mean } \pm \mathrm{SD})\end{array}$ & $\mathrm{F}$ & Partial $\eta^{2}$ & Post-hoc \\
\hline HADS (anxiety) & $6.51 \pm 5.76$ & $7.41 \pm 4.63$ & $11.41 \pm 6.36$ & $10.132^{* * *}$ & 0.126 & $\mathrm{a}<\mathrm{c}, \mathrm{b}<\mathrm{c}$ \\
\hline HADS (depression) & $7.83 \pm 5.33$ & $8.51 \pm 4.64$ & $11.45 \pm 5.47$ & $6.616^{* *}$ & 0.086 & $\mathrm{a}<\mathrm{c}, \mathrm{b}<\mathrm{c}$ \\
\hline PHQ-15 & $4.90 \pm 5.32$ & $7.59 \pm 4.15$ & $12.84 \pm 6.41$ & $27.898^{* * *}$ & 0.284 & $\mathrm{a}<\mathrm{c}, \mathrm{b}<\mathrm{c}$ \\
\hline CTQ-K & $43.49 \pm 13.16$ & $43.95 \pm 12.99$ & $42.48 \pm 16.28$ & 0.119 & 0.002 & ns \\
\hline
\end{tabular}

${ }^{* *} \mathrm{p}<0.01,{ }^{* * *} \mathrm{p}<0.001$. SD: standard deviation, FGID: functional gastrointestinal disorder, HADS: Hospital Anxiety Depression Scale, PHQ15: Patient Health Questionnire-15, CTQ-K: Childhood Trauma Questionnaire-Korean, ns: non-significant

Table 3. Comparison of health-related quality of life among the groups after adjusted for age and sex

\begin{tabular}{|c|c|c|c|c|c|c|}
\hline Variables & $\begin{array}{c}\text { Non-FGID }{ }^{\mathrm{a}} \\
(\mathrm{N}=63)(\text { mean } \pm \mathrm{SD})\end{array}$ & $\begin{array}{l}\text { Non-overlap FGID } \\
(\mathrm{N}=35)(\text { mean } \pm \mathrm{SD})\end{array}$ & $\begin{array}{c}\text { Overlap FGID } \\
(\mathrm{N}=46)(\text { mean } \pm \mathrm{SD})\end{array}$ & $\mathrm{F}$ & Partial $\eta^{2}$ & Post-hoc \\
\hline $\mathrm{PF}$ & $64.21 \pm 34.65$ & $57.57 \pm 36.69$ & $56.36 \pm 33.64$ & 0.786 & 0.011 & ns \\
\hline SR & $54.56 \pm 19.22$ & $54.73 \pm 21.11$ & $51.42 \pm 16.66$ & 0.436 & 0.006 & ns \\
\hline PR & $49.21 \pm 43.06$ & $35.81 \pm 36.10$ & $32.95 \pm 38.03$ & 2.542 & 0.035 & ns \\
\hline ER & $65.48 \pm 33.73$ & $50.68 \pm 30.33$ & $47.73 \pm 31.35$ & $4.691^{*}$ & 0.062 & $a>c$ \\
\hline $\mathrm{MH}$ & $56.89 \pm 21.33$ & $55.14 \pm 16.68$ & $40.00 \pm 22.66$ & $9.505^{* * *}$ & 0.119 & $a>c, b>c$ \\
\hline VT & $49.44 \pm 19.49$ & $45.41 \pm 18.57$ & $29.32 \pm 21.79$ & $13.733^{* * *}$ & 0.163 & $a>c, b>c$ \\
\hline BP & $59.72 \pm 34.08$ & $52.70 \pm 28.88$ & $42.04 \pm 33.46$ & $3.800^{*}$ & 0.051 & $a>c$ \\
\hline $\mathrm{GH}$ & $53.97 \pm 21.87$ & $50.27 \pm 16.79$ & $37.95 \pm 21.30$ & $8.168^{* * *}$ & 0.104 & $a>c, b>c$ \\
\hline PCS & $56.77 \pm 24.13$ & $49.08 \pm 19.61$ & $42.32 \pm 25.93$ & $4.908^{* *}$ & 0.065 & $a>c$ \\
\hline MCS & $56.59 \pm 14.97$ & $51.48 \pm 12.41$ & $42.11 \pm 17.07$ & $12.109^{* * *}$ & 0.147 & $a>c, b>c$ \\
\hline
\end{tabular}

${ }^{*} \mathrm{p}<0.05,{ }^{* *} \mathrm{p}<0.01,{ }^{* * *} \mathrm{p}<0.001$. ns: non-specificant, SD: standard deviation, FGID: functional gastrointestinal disorder, PF: physical functioning, SR: social role functioning, PR: physical role functioning, ER: emotional role functioning, MH: mental health, VT: vitality, BP: bodily pain, GH: general health perception, PCS: physical component summary, MCS: mental component summary

Table 4. Bivariate associations between severity of FGID and health related quality of life among overlap syndrome group ( $N=46)$

\begin{tabular}{llllll}
\hline & 1 & 2 & 3 & 4 & 5 \\
\hline PCS (1) & 1 & & & & \\
MCS (2) & $0.734^{* *}$ & 1 & & & \\
IBS-severity (3) & $-0.381^{* *}$ & $-0.403^{* *}$ & 1 & & \\
NERD-severity (4) & $-0.395^{* *}$ & $-0.441^{* *}$ & $0.625^{* *}$ & 1 & 1 \\
FD-severity (5) & $-0.298^{* *}$ & $-0.402^{* *}$ & $0.600^{* *}$ & $0.739^{* *}$ & $0.625^{* *}$ \\
FC-severity (6) & $-0.415^{* *}$ & $-0.386^{* *}$ & $0.628^{* *}$ & $0.612^{* *}$ & 1 \\
\hline
\end{tabular}

${ }^{* *} \mathrm{p}<0.01$. FGID: functional gastrointestinal disorders, PCS: physical component summary, MCS: mental component summary, NERD: nonerosive reflux disease, FD: functional dyspepsia, FC: functional constipation, IBS: irritable bowel syndrome 


\section{DISCUSSION}

In this study, we aimed to examine the psychosocial characteristics of psychiatric patients with FGID overlap syndrome. There were no statistically significant differences in demographic and clinical characteristics according to FGID.

Of the participants, 81 patients (56.25\%) showed FGID; this is higher than the prevalence of $49.7 \%$ reported by Park et al. ${ }^{27}$ in a study of patients at a digestive clinic, and much higher than the prevalence of $18.5 \%$ reported by Bang et al. ${ }^{28}$ in a study of military men experiencing high occupational stress. Also, unlike a previous study of the general population in South Korea, in which IBS-FD overlap was most common, ${ }^{29}$ in our study, NERD-FD overlap was most common. Avidan et al. ${ }^{30}$ reported that reflux symptoms were most severe in psychiatric patients, and suggested that the causes were 1) the effect of different psychiatric medication, 2) intrinsic psychological effect, and 3) indirect effect of an injurious lifestyle.

When we compared the psychological variables according to the FGID overlap diagnosis, the overlap group showed much higher depressive symptoms, anxiety, and physical symptoms than the other groups. Lee et al. ${ }^{31}$ reported that emotional stress and depression are independent risk factors for FD and IBS, and Pinto-Sanchez et al. ${ }^{32}$ reported that, within the FGID group, a greater number of FGIDs was associated with a proportional increase in depression and anxiety. Recent animal studies have proposed a brain-gut-microbiome axis, in which stress changes the composition of the microbiome, the microbiota, in turn, alter metabolism and transmission of brain-derived neurotrophic factor (BDNF), gammaaminobutyric acid (GABA), and serotonin, and this influences depression and anxiety. ${ }^{33}$ Vanuytel et al. ${ }^{34}$ reported that increased corticotrophin releasing hormone (CRH) in the event of acute emotional stress alters intestinal permeability via the action of mast cells, and that $\mathrm{CRH}$ and mast cells also affect visceral sensitivity. ${ }^{35}$

Because FGID is chronic disease, patients are apt to experience loss of autonomy. Thus, FGID patients exhibit high levels of anxiety and depression. Conversely, high levels of depression and anxiety can cause various symptoms of FGID or worsen the severity of the symptoms. However, it is difficult to clarify the causal relationship between them. Therefore, further studies on the link between FGID and anxiety and depression in animals and humans are needed.

Notably, one previous study proposed that childhood trauma is an important factor in the development of FGID, ${ }^{36}$ but our study found no differences when we compared childhood trauma between groups with and without the overlap syndrome. Levy et al. ${ }^{37}$ explained the effects of childhood trauma on FGID in terms of concurrent psychiatric disorders, altera- tion of bodily symptoms, impaired adult relationships, centrally lowered threshold for perceiving afferent GI signals, and increased autonomic function and/or intestinal motility due to hyperarousal. In psychiatric patients, the effects of comorbid psychiatric disease are limited, and it is likely that there was a recall bias in the process of recalling childhood trauma that occurred a long time ago.

When we examined differences in QOL according to FGID overlap, the overlap group showed lower scores in all subdomains of the SF-36 except for PF, SR, and PR. In a previous study, Choi et al. ${ }^{38}$ reported that multiple FGID patients experienced much lower QOL than single FGID patients, and that, in FGID patients, somatic symptoms related to FGID were the most important factors for QOL. Kaji et al..$^{39}$ also reported lower QOL in FD-IBS overlap patients compared to a control group, and that mental component was the most important factor in determining QOL. PCS and MCS also showed very strong correlations with FGID symptoms severity. Therefore, going forward, FGID-specific psychosocial interventions can be considered to be very important for improving not only somatic symptoms, but also for QOL and the recovery of everyday function in FGID patients.

This study had several limitations. First, because data was collected using a retrograde self-report scale, we cannot exclude the possibility of a recall bias. Second, because it uses cross-sectional data, causal inference may be unclear. Third, the study implemented questionnaire-based screening for FGID using the Rome III diagnostic criteria, and thus there was no assessment of any underlying gastrointestinal pathology. Fourth, because the study was restricted to psychiatric patients only, there are limitations in generalizing the results.

Nevertheless, the value of this study is that we ascertained the prevalence and psychosocial characteristics of FGID overlap syndrome in psychiatric patients with very severe psychological distress. In addition, we assessed not only differences in the QOL with FGID, but also the relation between QOL and the severity of individual FGID symptoms. In future clinical assessments and treatment of FGID, diverse efforts will be required to improve symptoms and QOL through FGIDspecific psychosocial interventions.

\section{Acknowledgments}

This study was supported by Wonkwang University in 2019.

\section{Conflicts of Interest}

The author has no potential conflicts of interest to disclose.

\section{Author Contributions}

Conceptualization: Seung-Ho Jang, Sang-Yeol Lee. Methodology: SuckChei Choi, Seung-Ho Jang. Investigation: Han-Seung Ryu, Seung-Ho Jang. Resources: Suck-Chei Choi, Han-Seung Ryu, Seung-Ho Jang. Writingoriginal draft preparation: Seung-Ho Jang, Han-Seung Ryu. Writing-re- 
view \& editing: Seung-Ho Jang, Sang-Yeol Lee. Supervision: Seung-Ho Jang, Sang-Yeol Lee.

\section{ORCID iDs}

Sang-Yeol Lee

Han-Seung Ryu

Suck-Chei Choi

Seung-Ho Jang https://orcid.org/0000-0003-1828-9992

https://orcid.org/0000-0002-9359-0075

https://orcid.org/0000-0003-1338-3306

https://orcid.org/0000-0002-3479-0552

\section{REFERENCES}

1. Drossman DA. The functional gastrointestinal disorders and the Rome III process. Gastroenterology 2006;130:1377-1390.

2. Gwee KA, Bak YT, Ghoshal UC, Gonlachanvit S, Lee OY, Fock KM, et al. Asian neurogastroenterology and motility association. Asian consensus on irritable bowel syndrome. J Gastroenterol Hepatol 2012;25: 1189-1205.

3. Seres G, Kovács Z, Kovács A, Kerékgyártó O, Sárdi K, Demeter P, et al. Different associations of health-related quality of life with pain, psychological distress and coping strategies in patients with irritable bowel syndrome and inflammatory bowel disorder. J Clin Psychol Med S 2008;15: 287-295.

4. Wang YT, Lim HY, Tai D, Krishnamoorthy TL, Tan T, Barbier S, et al. The impact of irritable bowel syndrome on health-related quality of life: a Singapore perspective. BMC Gastroenterol 2012;12:104.

5. Bennett EJ, Piesse C, Palmer K, Badcock CA, Tennant CC, Kellow JE. Functional gastrointestinal disorders: psychological, social, and somatic features. Gut 1998;42:414-420.

6. Lee SP, Sung IK, Kim JH, Lee SY, Park HS, Shim CS. The effect of emotional stress and depression on the prevalence of digestive diseases. J Neurogastroenterol Motil 2015;21:273-282.

7. Thijssen AY, Jonkers DM, Leue C, van der Veek PP, Vidakovic-Vukic M, van Rood YR, et al. Dysfunctional cognitions, anxiety and depression in irritable bowel syndrome. J Clin Gastroenterol. 2010;44:e236-e241.

8. Oreški I, Jakovljević M, Aukst-Margetić B, Crnčević Orlić Ž. VuksanĆusa B. Comorbidity and multimorbidity in patients with schizophrenia and bipolar disorder: similarities and differencies. Psychiatr Danub 2012;24:80-85.

9. Molloy CA, Manning-Courtney P. Prevalence of chronic gastrointestinal symptoms in children with autism and autistic spectrum disorders. Autism 2003;7:165-171.

10. Lydiard RB, Fossey MD, Marsh W, Ballenger JC. Prevalence of psychiatric disorders in patients with irritable bowel syndrome. Psychosomatics 1993;34:229-234.

11. Noyes R, Cook B, Garvey M, Summers R. Reduction of gastrointestinal symptoms following treatment for panic disorder. Psychosomatics 1990; 31:75-79.

12. Suzuki H, Hibi T. Overlap syndrome of functional dyspepsia and irritable bowel syndrome - are both diseases mutually exclusive? J Neurogastroenterol Motil 2011;17:360-365.

13. Locke GR, Zinsmeister AR, Fett SL, Melton LJ, Talley NJ. Overlap of gastrointestinal symptom complexes in a US community. Neurogastroenterol Motil 2005;17:29-34.

14. Choung RS, Chang JY, Locke GR, Schleck CD, Zinsmeister AR, Talley NJ. Is having multiple functional gastrointestinal disorders distinct from having a single FGID? A population based study. Gastroenterology 2011; 140:S708.

15. American Psychiatric Association. Diagnostic and Statistical Manual of Mental Disorders. 5th Ed. Arington, VA: American Psychiatric Publishing; 2013.

16. Vakil N, van Zanten SV, Kahrilas P, Dent J, Jones R. The montreal definition and classification of gastroesophageal reflux disease: a global evidence-based consensus. Am J Gastrol 2006;101:1900-1920.

17. Zigmond AS, Snaith RP. The hospital anxiety and depression scale. Acta Psychiatr Scand 1983;67:361-370.

18. Oh SM, Min KJ, Park DB. A study on the standardization of the hospi- tal anxiety and depression scale for Koreans. J Korean Neuropsychiatr Assoc 1999;38:289-296.

19. Bernstein DP, Fink L, Handelsman L, Lovejoy M, Wenzel K, Sapareto E, et al. Initial reliability and validity of a new retrospective measure of child abuse and neglect. Am J Psychiatry 1994;151:1132-1136.

20. Kim DH, Park SC, Oh DH. Reliability and validity of the Korean version of the childhood trauma questionnaire-short form for psychiatric outpatients. Psychiatry Investig 2011;8:305-311.

21. Kroenke K, Spitzer RL, William JB. The PHQ-15: Validity of a new measure for evaluating the severity of somatic symptoms. Psychosom Med 2002;64:258-266.

22. Han CS, Pae CU, Patkar AA, Masand PS, Kim KW, Joe SH, et al. Psychometric properties of the patient health questionnaire-15 (PHQ-15) for measuring the somatic symptoms of psychiatric outpatients. Psychosomatics 2009;50:580-585.

23. Ware JE Jr, Sherbourne CD. The MOS 36-item short-Form Health Survey (SF-36): I. Conceptual framework and item selection. Med Care 1992;30:473-483.

24. Han CW, Lee EJ, Iwaya T, Kataoka H, Kohzuki M. Development of the Korean version of short-form 36 item health survey: health related QOL of healthy elderly people and elderly patients in Korea. Tohoku J Exp Med 2004;203:189-194.

25. Drossman DA, Li Z, Toner BB, Diamant NE, Creed FH, Thompson D, et al. Functional bowel disorders. A multicenter comparison of health status and development of illness severity index. Dig Dis Sci 1995;40:986-995.

26. Cohen J. Statistical Power Analysis for the Behavioral Sciences. New York, London: Psychology Press; 1998.

27. Park JM, Choi MG, Cho YK, Lee IS, Kim JI, Kim SW, et al. Functional gastrointestinal disorders diagnosed by Rome III questionnaire in Korea. J Neurogastroenterol Motil 2011;17:279-286.

28. Bang CS, Kim YS, Han JH, Lee YS, Baik GW, Kim JB, et al. Functional gastrointestinal disorders in young military men. Gut Liver 2015;9: 509-515.

29. Park H. Functional gastrointestinal disorders and overlap syndrome in Korea. J Gastroenterol Hepatol 2011;26(Suppl 3):12-14.

30. Avidan B, Sonnenberg A, Giblovich H, Sontag SJ. Reflux symptoms are associated with psychiatric disease. Aliment Pharmacol Ther 2011;15: 1907-1912.

31. Lee SP, Sung IK, Kim JH, Lee SY, Park HS, Shim CS. The effect of emotional stress and depression on the prevalence of digestive diseases. J Neurogastroenterol Motil 2015;21:273-282.

32. Pinto-Sanchez MI, Ford AC, Avila CA, Verdu EF, Collins SM, Morgan D. Anxiety and depression increase in a stepwise manner in parallel with multiple FGID and symptom severity and frequency. Am J Gastroenterol 2015;110:1038-1048.

33. Foster JA, Neufeld KA. Gut-brain axis: how the microbiome influences anxiety and depression. Trends Neurosci 2013;36:305-312.

34. Vanuytsel T, Van Wanrooy S, Vanheel H, Vanormelingen C, Verschueren S, Houben E, et al. Psychological stress and corticotropin-releasing hormone increase intestinal permeability in humans by a mast cell-dependent mechanism. Gut 2014;63:1293-1299.

35. Larauche M. Novel insights in the role of peripheral corticotropin-releasing factor and mast cells in stress-induced visceral hypersensitivity. J Neurogastroenterol Motil 2012;2:201-205.

36. Drossman DA. Leserman J, Nachman G, Li Z, Gluck H, Toomey TC, et al. Sexual and physical abuse in women with functional or organic gastrointestinal disorders. Ann Intern Med 1990;113:828-833.

37. Levy RL, Olden KW, Naliboff BD, Bradley LA, Francisconi C, Drossman DA, et al. Psychosocial aspects of the functional gastrointestinal disorders. Gastroenterol 2006;130:1447-1458.

38. Choi MG, Jung HK. Health related quality of life in functional gastrointestinal disorders in Asia. J Neurogastroenterol Motil 2011;17:245-251.

39. Kaji M, Fujiwara Y, Shiba M, Kohata Y, Yamagami H, Tanigawa T, et al. Prevalence of overlaps between GERD, FD and IBS and impact on health-related quality of life. J Gastroenterol Hepatol 2010;25:11511156. 